DOE/mc/31203--01

RECEIPRERE:-94MC31203-01

SEP 251009

ost:

\title{
Characterization and Failure Analysis of Ceramic Filters Utilized for Emission Control During Coal Gasification
}

\author{
Quarterly Report \\ July 1 - September 30, 1996
}

\author{
By \\ Ziaul Huque \\ Daniel Mei \\ Jianren Zhou
}

Work Performed Under Contract No.: DE-FG21-94MC31203

\author{
For \\ U.S. Department of Energy \\ Office of Fossil Energy \\ Federal Energy Technology Center \\ P.O. Box 880 \\ Morgantown, West Virginia 26507-0880 \\ By \\ Prairie View A\&M University \\ College of Engineering and Architecture \\ P.O. Box 397 \\ Prairie View, Texas 77446-0397
}




\section{Disclaimer}

This report was prepared as an account of work sponsored by an agency of the United States Government. Neither the United States Government nor any agency thereof, nor any of their employees, makes any warranty, express or implied, or assumes any legal liability or responsibility for the accuracy, completeness, or usefulness of any information, apparatus, product, or process disclosed, or represents that its use would not infringe privately owned rights. Reference herein to any specific commercial product, process, or service by trade name, trademark, manufacturer, or otherwise does not necessarily constitute or imply its endorsement, recommendation, or favoring by the United States Government or any agency thereof. The views and opinions of authors expressed herein do not necessarily state or reflect those of the United States Government or any agency thereof. 


\section{DISCLAIMER}

Portions of this document may be illegible electronic image products. Images are produced from the best available original document. 
The research activities performed at $\mathrm{PV} \mathrm{A \& M}$ University in the reporting period of $07 / 01 / 96$ to $09 / 30 / 96$ are summarized below.

- To evaluate IF\&P filter samples as well as different type of filters and provide test data as a data base to verify gas stream flow numerical simulation of a filter test chamber, the research efforts planned at PV A\&MU include the following areas:

- Filter permeability characterization and flow rate measurement under controlled environments

- Back pulse cleaning mechanism studies for single filter

- Back pulse pressure distribution measurement within candle filter without dust cake

- Pressure field measurement outside filter(s) during gas flowing process

- Optimization on back pulse system test design

For room temperature filter study, the research work performed are described below.

- To characterize the physical properties of ceramic candle filter gas flow properties, the new test facility was complete. The test facility includes the following sub-assemblies:

1) Filter test chamber assembly at room temperature - a transparent plastic pipe for phase one filter testing and filter characterization. Ten 1/4--20 threaded holes are evenly spaced on the six (6) inches O.D. by ten (10) foot long transparent pipe along filter axis. The ten threaded holes are designed for transducers mounting and pressure source input port during filter testing. This feature will facilitate pressure flow configuration control, pressure distribution monitoring during inlet gas flow and back pulse cleaning processes.

2) Pressure calibration facility - the advanced micro-processor based hand held pressure calibrator and two pressure modules, a 100 psig module and a 250 inches of water differential pressure module, were utilized for pressure transducer calibration and filter permeabilty performance evaluation at room temperature. The hand held pressure calibrator is capable of calculating the flow rate and gas leak rate besides pressure monitoring and measurements. The test setup had been pressure proof tested with the use of this pressure calibrator.

3) High speed pressure transducers - eight of 30 psig micro-machined silicon transducers had been installed along the axis of the filter chamber to get ready to characterize filter permeability and the pressure distribution within the filter chamber. 15 psia and 100 psig pressure transducers will also be utilized for pressure field measurement. 
4) Filter permeability simulation - a technique had been successfully developed to seal the filter surface. This sealing technique will facilitate the testing for filter permeability evaluation and back pulse pressure distribution with preset filter surface blockage. The permeability distribution of IF\&P filters will be carefully measured and characterized along the axis of the filters with different exposure percentage of filter surfaces to the gas flow. Detail filter surface exposure test plan will be based on preliminary filter test results.

5) Data acquisition system - an advanced data acquisition system had been acquired to collect test data automatically. Hardware installation was in the installation process, and the students were instructed to learn software programming.

6) A perforating diaphragm assembly - a chamber pressure holding assembly had been complete. The pressure sealing diaphragm is capable to seal filter test chamber pressure, and the sealing diaphragm is to be perforated by this special designed device to release chamber pressure per the test plan. This assembly can work under positive pressure and vacuum environments. Positive pressure will be provided by nitrogen bottle. Vacuum environment will be support by a vacuum system which has been designed and acquired.

Negative pressure would be supplied to the filter test chamber with the use of the diaphragm sealing technique. The back pulse pressure can be created at various pressure ranges, sealed by the diaphragm per the vacuum pressure level maintained in the filter chamber. Pressure distribution can be measured systematically with this setup. Back pulse inlet configuration could also be designed and optimized with a uniform back pulse flow versus a lance induced jet flow.

Back pulse intensity could be evaluated with both positive and negative pressure supply outside and inside the filter chamber. The more expensive exterior positive back pressure testing can be optimized based on the vacuumed chamber back pressure testing.

The hardware installation of the advanced data acquisition was complete. More efforts were emphasized on the software programming and configuration of the data acquisiton related boards to acquire testing data.

An improved diaphragm perforating design was complete. A new diaphragm perforating device was made, and its performance was successful. Test data are more repeatable with the use of the new device.

A relative measure was utilized to characterize the variations of filter permeability by counting the total leak time required for the positive chamber pressure to reduce to the ambient pressure. The source of the positive pressure was provided from a pressurized nitrogen bottle.

A vacuum pump would be utilized to create a vacuum environment for the back pulse cleaning process study. 
The vacuum environment testing procedures would be generated after filter permeability variation study.

To character IF \&P filter performance, permeability changes of unused and used filters were first evaluated within an innovative test setup assembled in the mechanical engineering laboratory at Prairie View A\&MU.

To ensure the validity of the test results, the test setup and controls had been modified and improved until repeatable test environment and controls were available.

The permeability distribution of IF\&P filters was then carefully measured and characterized along the axis of the filters with different exposure percentage of filter surfaces to the gas flow.

To facilitate the characterization of filter permeability variations, it was decided that only $25 \%$ of the filter surface was evaluated each time after a few test iterations.

Each filter was tested four times with the same test environment under one pressure range. And every test was repeatedly performed five times. After reviewing, the test results were found to be repeatable and representative as planned.

The test data indicated that the unused filter is characterized with a fairly uniform permeability distribution along its axis; however, the used filter displayed a random and non uniform permeability distribution along its axis, when both type of filters were tested under the same environment with the same test setup.

Based on the test results, a research paper was presented and accepted by European Biannual Particulate Cleanup Conference, sponsored by the U.S. ASME. This paper is entitled as "Effect of Pressure Distribution And Back Pulse On the Failure Of Ceramic Filters Used For Emission Control During Coal Gasification.", completed by Roksana Khan, the graduate student, Dr. Ziaul Huque and Dr. Daniel Mei.

This finding would be further evaluated with more filter samples from IF\&P and filters fabricated by different filter manufacturers. The detail test plan and the percentage of filter surface exposure would be revised according to more filter test results.

These test data can be served as a preliminary filter performance data base to support numerical simulation analysis, back pulse cleanup optimization and filter failure analysis.

As more test data are collected at PV A\&MU, it could be utilized to support professor M. Jhon of Carnegie Mellon University and professor G. Ahmadi of Clarkson University on the verification of their numerical simulation analysis for back pulse flow and particulate flow pattern per PV A\&MU research setup configuration.

Following the same test plan, PV A\&MU could report all of the test data to D.O.E. to support filter research institutes and filter industry for as required. 
Detail drawing of the bench scale ceramic candle filter test arrangement (modified) was complete. Figure 1 shows the modified drawing.

To characterize IF\&P filter performance, permeability changes of unused and used filters were carefully repeatedly tested. Figure 7 shows the curves for circumferential permeability variations. The used filter demonstrated its permeability variations in both axial and circumferential directions with random modes.

Figure 2, 3, 4, 5 and 6 show the sensor pressure readings at different axial locations along the filter axis external of the filter in the filter test chamber.

Pressure fluctuations were observed within candle filters along filter axis as the gas stream filtered through the filter wall. the pressure fluctuations are also consistent with the permeability variations of the filter under test. A small scale of reverse flow were also observed within the filter cavity with a flow pattern similar to the pressure field external of the filter.

All of the above tests were repeated many times and they repeat very well. The test data indicated that the permeability variations along the filter can be randomly distributed; and it could be history dependent.

Considering that the mechanical, thermal and chemical failure all should have its special marks on microstructure and composition changes, the microstructure and composition of the unused and used ceramic filter have been examined by SEM, X-ray diffractometer (XRD). The purpose is to identify whether changes in microstructure of the post-run filter have occurred and how it affect the function and durability of the ceramic filters.

The used filter has same main composition of silicon carbide, same manufacture process (clay-bond sintered), same size and shape as unused one. The unused ceramic filter is a porous candle with gray color and double layers. The used filter has been run under following condition for a period of time: Gas temperature $=650^{\circ} \mathrm{C}$, Gas pressure $=20 \mathrm{~kg} / \mathrm{cm}^{2}$, Jet pulse pressure $=35 \mathrm{~kg} / \mathrm{cm}^{2}$, Jet pulse duration $=1.0$ Second. It is in dark yellow color on surface and broken in a location near flange.

From the filtration process analysis, it has been known that dark yellow color dust layer on the used filter is the product of the emission particle build up during coal gasification process and the chemical reaction product between the emission gases and ceramic filter compositions. This dust materials reduce the permeability and increases the pressure drop through filter, and so, reduce the efficiency of the filter and may be lead to the ceramic filter failure sequentially. X-ray diffraction in Figure7 shows that the main phase compositions of this dust layer are $\mathrm{SiO}_{2}, \mathrm{Al}_{2} \mathrm{O}_{3}$ and $\mathrm{Al}_{2} \mathrm{Si}_{4} \mathrm{O}_{10}$. It is very easy to eliminate it from the surface of the used filter by ultrasonic cleaning. 
The micrographs of the unused and used filters were presented in Figure 10 . The microstructures of the filter can be divided into three regions. The first one is the outer layer with a fine microstructure which is corresponding to the aluminosilicate membrane of ceramic filter. The second one is the inner layer with coarse grains which is corresponding to the support matrix (clay-bonded silicon carbide) of the ceramic filter. The third one is the interfacial region between the first and second layers. In this region the microstructure transforms from one to another. Although there is no abrupt transition on the interface microstructure, the differences of microstructure in two region is still easy to tell. The first layer has a porous cotton-like microstructure. The diameter of the pores is around several tens of micrometer. The second layer has a porous microstructure too. In Figures 12 and 13 the big particles (several tens micrometer in size) are bonded by clay and the pores are formed in the boundary between the particles.

Table 1 Analysis results of the XRD on unused and used ceramic filters

\begin{tabular}{|c|c|c|c|c|}
\hline \multicolumn{3}{|l|}{ Unused filter } & \multicolumn{2}{|c|}{ Used ceramic filter } \\
\hline & Outer layer & Inner layer & Outer layer & Inner layer \\
\hline Possible phase & $\mathrm{SiC}, \mathrm{Al}_{2} \mathrm{Si}_{4} \mathrm{O}_{10}$ & $\mathrm{SiC}$ & $\mathrm{SiC}, \mathrm{Al}_{2} \mathrm{Si}_{4} \mathrm{O}_{10}$ & $\mathrm{SiC}$ \\
\hline Crystal constant (a) of $\mathrm{SiC}$ & 3.070 & 3.088 & 3.081 & 3.090 \\
\hline Crystal constant (c) of $\mathrm{SiC}$ & 127.47 & 114.42 & 128.19 & 128.88 \\
\hline $\begin{array}{l}\text { Crystal plane used in } \\
\text { calculation of a, c values }\end{array}$ & $\begin{array}{lll}\left(\begin{array}{lll}0 & 1 & 68\end{array}\right) \\
\left(\begin{array}{lll}2 & 0 & 17\end{array}\right) \\
\end{array}$ & 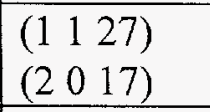 & 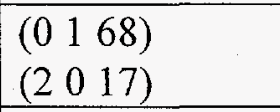 & $\begin{array}{l}\left(\begin{array}{lll}0 & 1 & 68\end{array}\right) \\
\left(\begin{array}{lll}2 & 0 & 2\end{array}\right)\end{array}$ \\
\hline $\begin{array}{l}\text { Crystal plane with highest } \\
\text { diffraction intensity }\end{array}$ & $\left(\begin{array}{llll}0 & 1 & 17\end{array}\right)$ & $\left(\begin{array}{llll}0 & 1 & 17\end{array}\right)$ & $\left(\begin{array}{llll}0 & 1 & 17\end{array}\right)$ & $\left(\begin{array}{lll}1 & 0 & 34\end{array}\right)$ \\
\hline
\end{tabular}

Figures 8, 9 and Table 1 summarize the XRD test and analysis results of the unused and used ceramic filters. They showed that after usage the crystal structures of the main composition, $\mathrm{SiC}$, in both layers of the ceramic filter have been changed. The crystal constants of the $\mathrm{SiC}$ in the outer layer were increased. For the inner layer, not only have the crystal constants of the $\mathrm{SiC}$ been increased, the grain orientation has also been changed. The preferred orientation along ( $\left.\begin{array}{lll}1 & 0 & 34\end{array}\right)$ of $\mathrm{SiC}$ in the inner layer of the used ceramic filter can be seen clearly in Figure 9 . The results indicate that recrystallization or phase transformation process of the $\mathrm{SiC}$ occurred during usage of the ceramic filter in the elevated temperature environment. The expansion of volume caused by growing and change in microstructure of the grain may result in great stress inside the filter, which may further promote the nucleation and propagation of the microcracks at the positions where inclusion and defects exist, and lead to the final fatigue fracture failure of the ceramic filters. It is shown in Figure 11. Particularly, the inconsistency in change of crystal constants and structure between inner and outer layers would cause delamination of the ceramic filter, which can be seen in Figure 10. The unused filter has a good combination between inner and outer layers, while the used filter show that some particles have dropped off the combination part. Meanwhile, the grain growing and volume expansion may lead to the reduce of the volume ratio of the pores, and as a result, decrease the permeability of the ceramic filters, see comparing of the microstructures of the used and unused ceramic filters shown in Figures 12 and 13. 
Observation of the post-run filters gave out that there are many cracks on the surface of the failed ceramic filter. Some of them caused fracture failure of the ceramic filter, they developed along longitude first and then deflected in 45 degree; the others had not propagated too much and met together. The morphological features of the fractured surface of the ceramic filter was illustrated in Figure 14. The broken surface of the filter candle indicates fatigue fracture process occurred, which resulted in the final failure of the ceramic filter. The structural stress discussed above and thermal stress caused by back-pulse cleaning may be responsible for the initiation and propagation of the microcracks. The more detailed experimental studies and theoretical analysis related to crack initiation and fracture process will be performed in the near future.

Trouble shooting and repairing of the sputtering deposition system has been almost finished. The new gold and silver targets for the deposition chamber have been ordered and replaced. The high voltage electrical source has been checked and repaired. The only problem left is the bad vacuum gage meter, which will be replaced by a new one.

Ceramic cutting and polishing machines and scanning electron microscope (SEM) have been maintained and been ready to work.

Dr. Huque, Dr. Mei and Dr. Zhou attended the advanced coal power conference held at METC in July. They attended the Post Session to present their research work performed at PV A\&MU on the Initial Study Of Ceramic Failure Analysis. Many researchers and institutes were interested in the variations of filter permeability.

Westinghouse decided to provide PV A\&MU with their tested filters for the permeability variation evaluations.

Researchers were interested to work with PV A\&MU to verify their numerical study on filtered gas flow pressure field in filter test chamber.

Dr. Mei had put efforts in programming instrumentation interfacing drivers for RS 232, RS 485 and IEEE 488 to facilitate data acquisition with more instrumentation devices connected to the current tet system.

Westinghouse had provided PV A\&MU with four filters. These filters are longer than the filters tested in the current test system ( 1.5 meter long rather than 1.0 meter). Dr. Mei is working the design to modify the current test facility to continue the filter evaluation.

PV A\&MU is expecting to receive filter sample from IF\&P to perform the same type of testing. 
All the filters to be evaluated at PV A\&MU facility will be carefully identified with its history to correlate the performance and its service background and environment for a better understanding of the primary factors contributing to the changes of filter properties and/or past filter failures.

\section{Future Plan of Action}

- Complete filters permeability variation study

- Study on filter cluster pressure field

- Study on back pulse cleaning process

- Optimization testing of back pulse study

- Study and comparison of filter material on composition, state, microstructure and crack 
DLAPHRÄGM PLACING CYLINDER

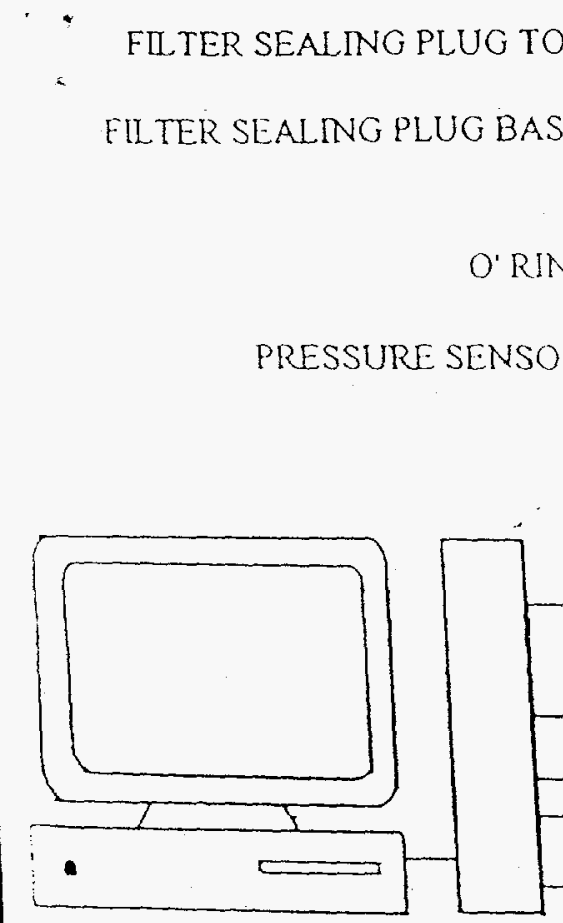

TA ACQUISITION SYSTEM

HAND HELD PRESSURE CALIBRATOR

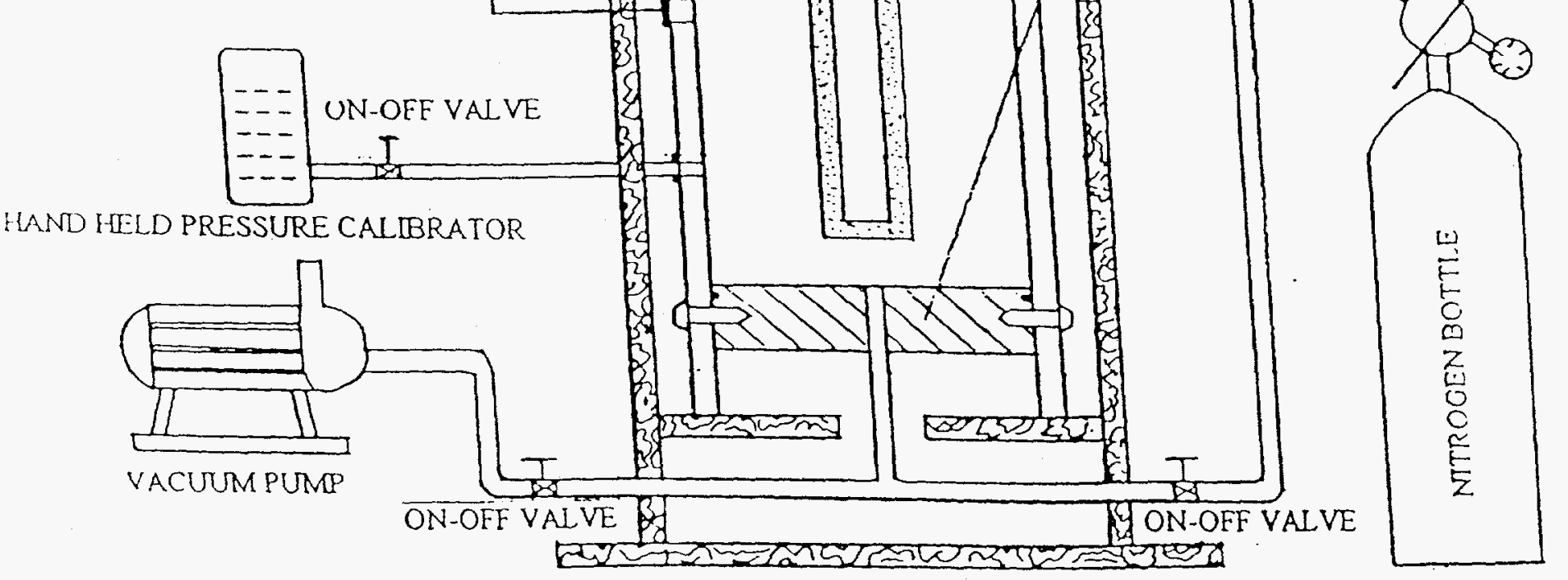

VACUUM PUMP

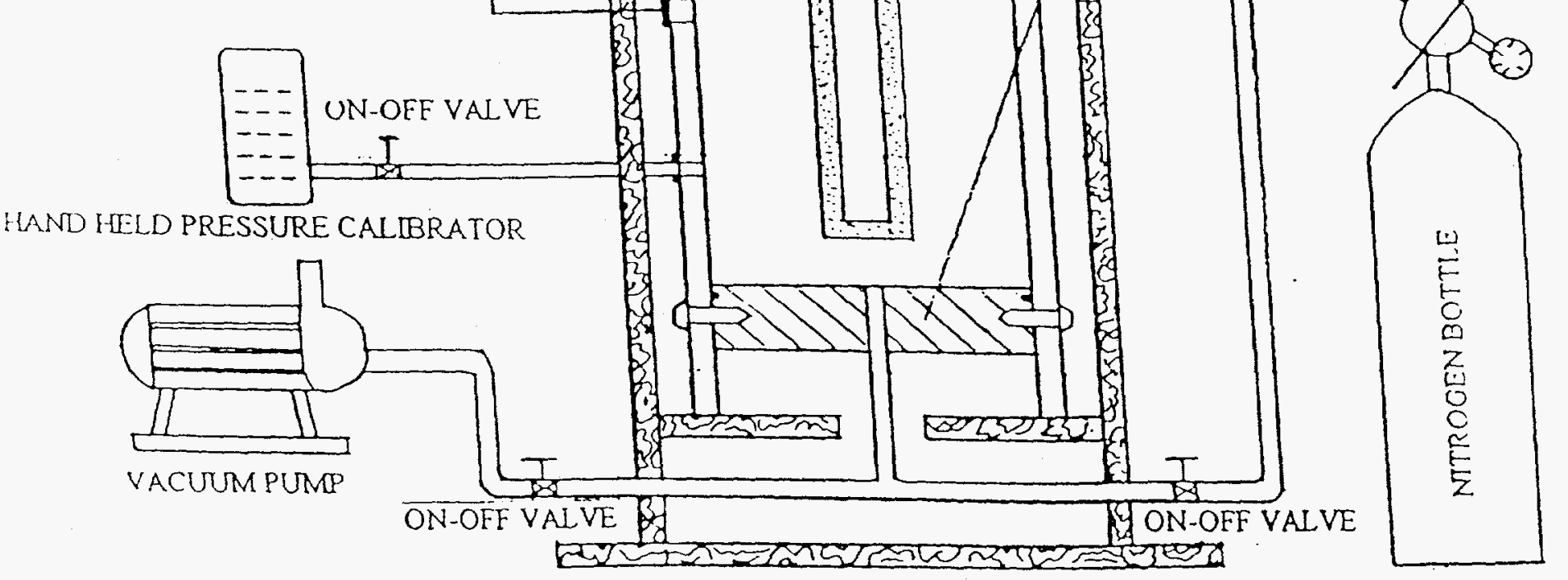

Fig. 1 SCHEMATIC DIAGRAM FOR UNNUSED ANND USED CERAMIC FILTER TEST 


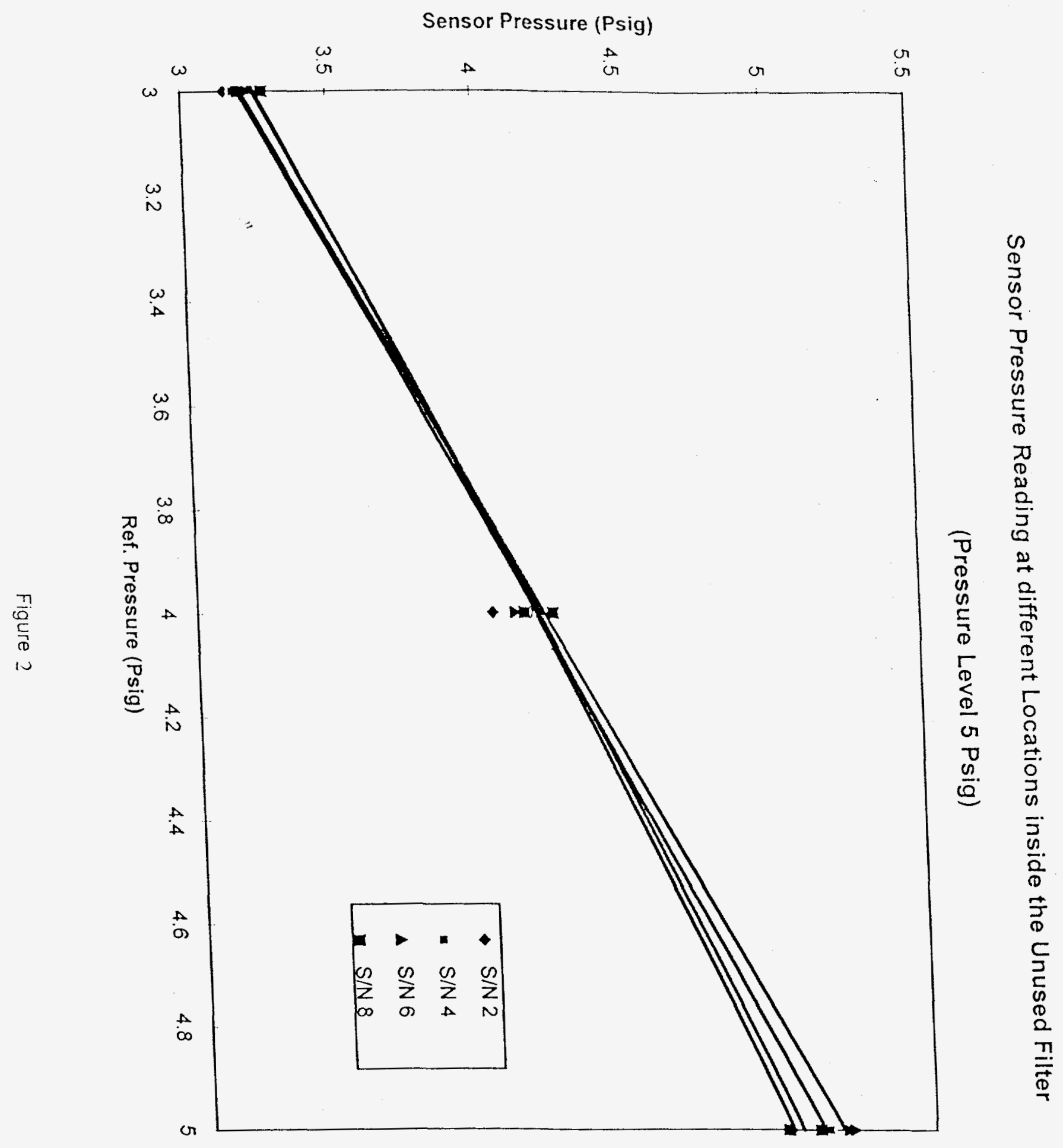




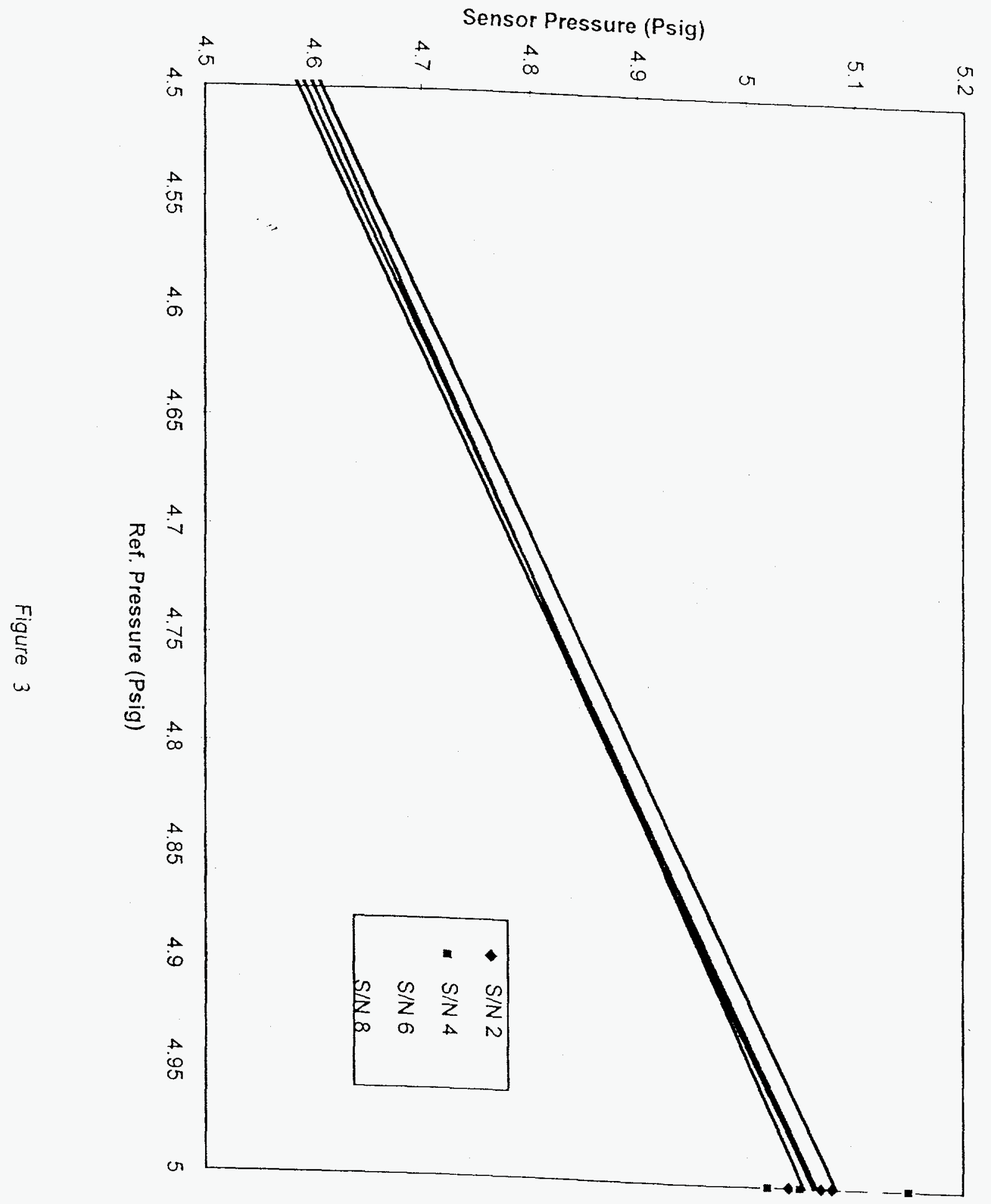

0
$\frac{0}{3}$
0
0
1 
Sensor Pressure Reading at different Outside Location of unused Filter (Pressure Level 20 Psig)

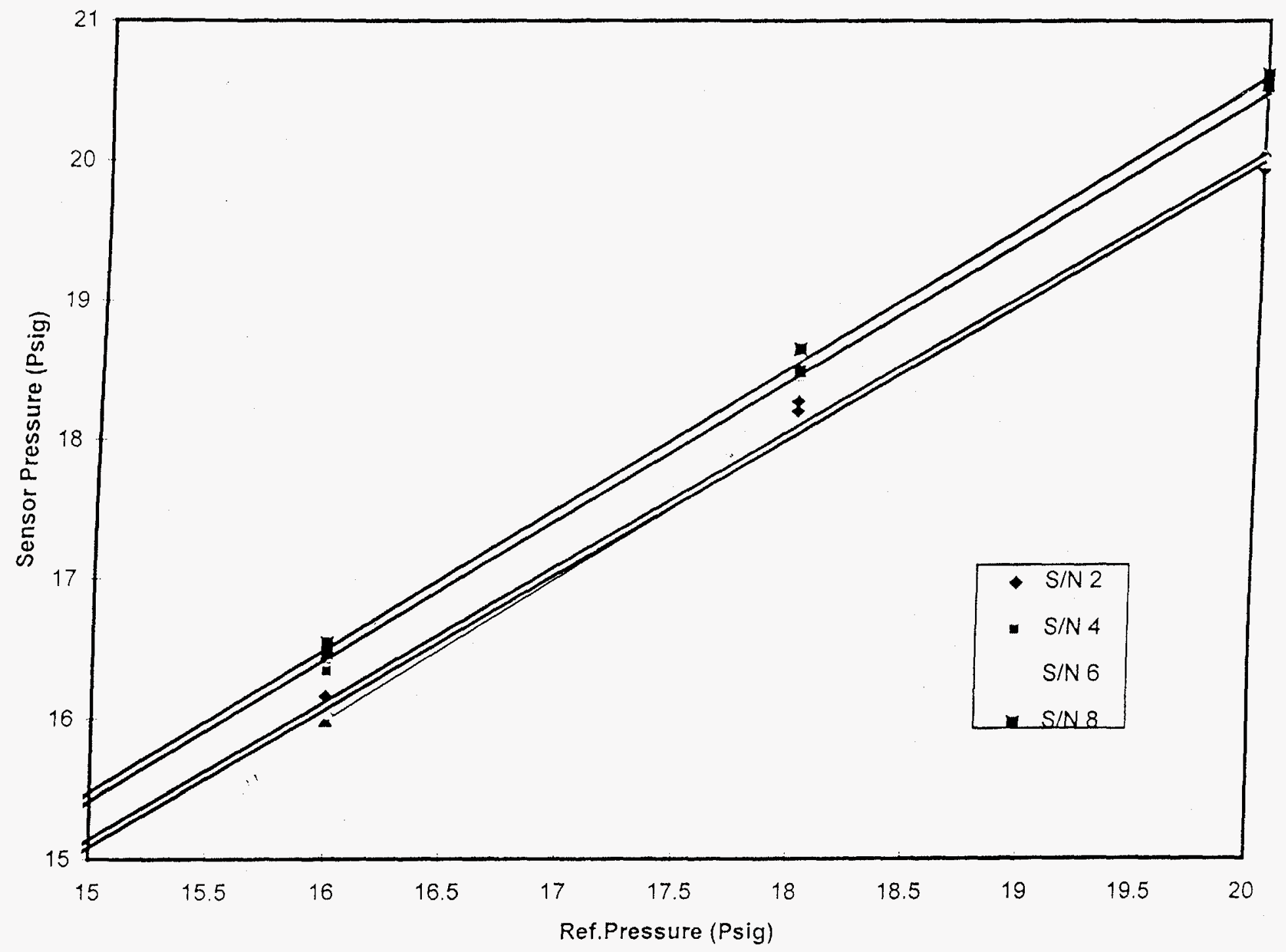

Figure 4 
Sensor Pressure (Psig)

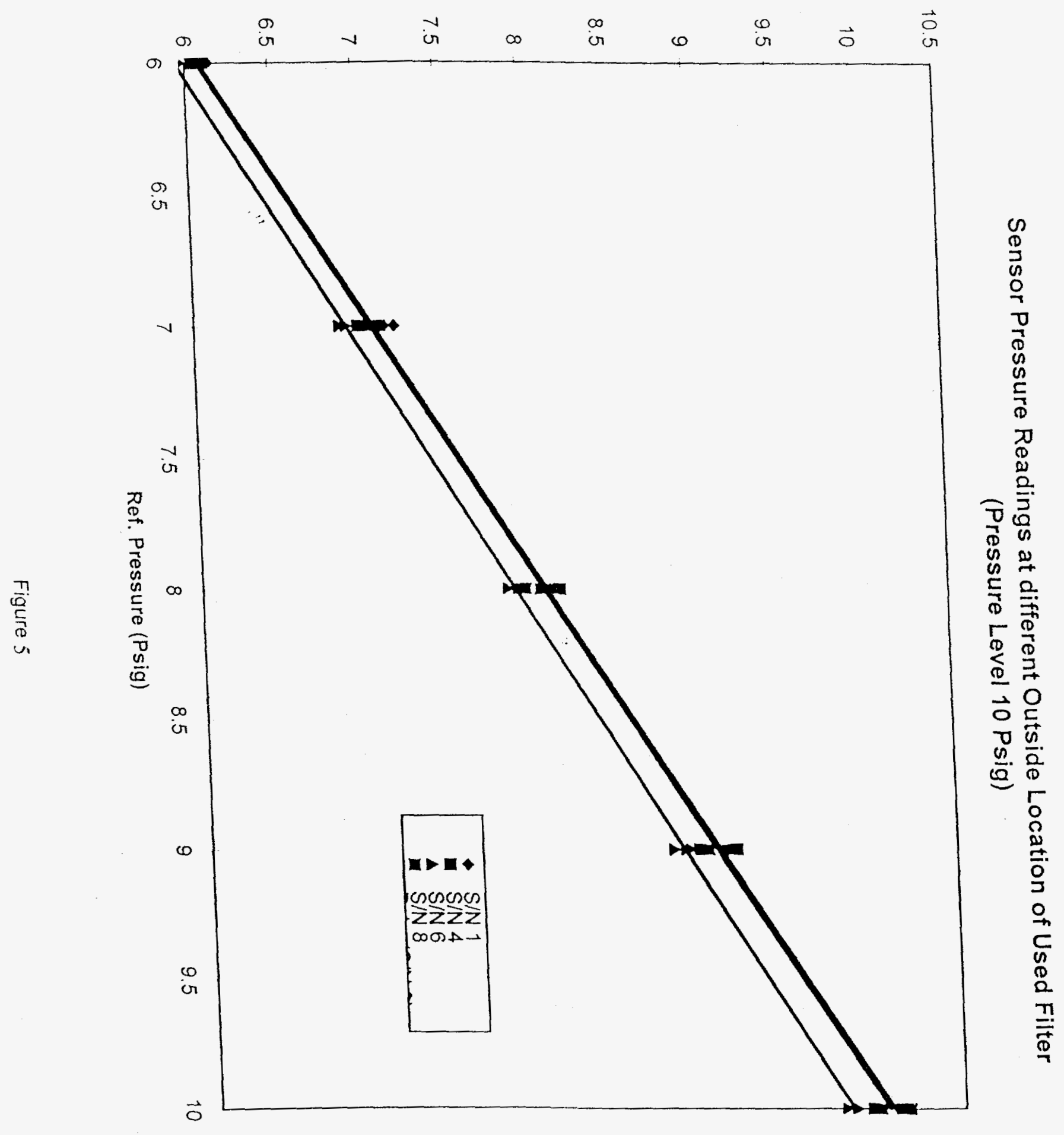




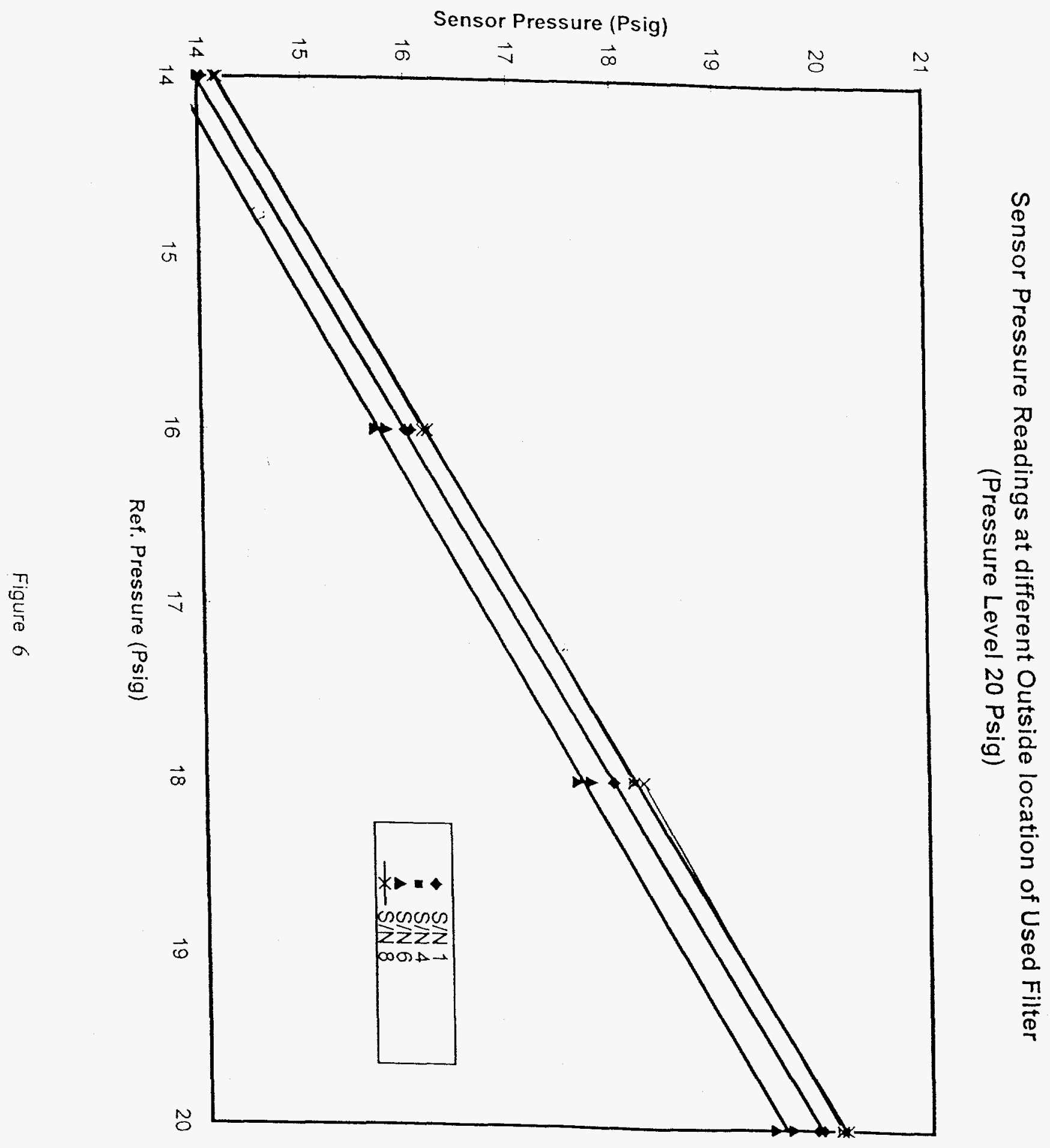




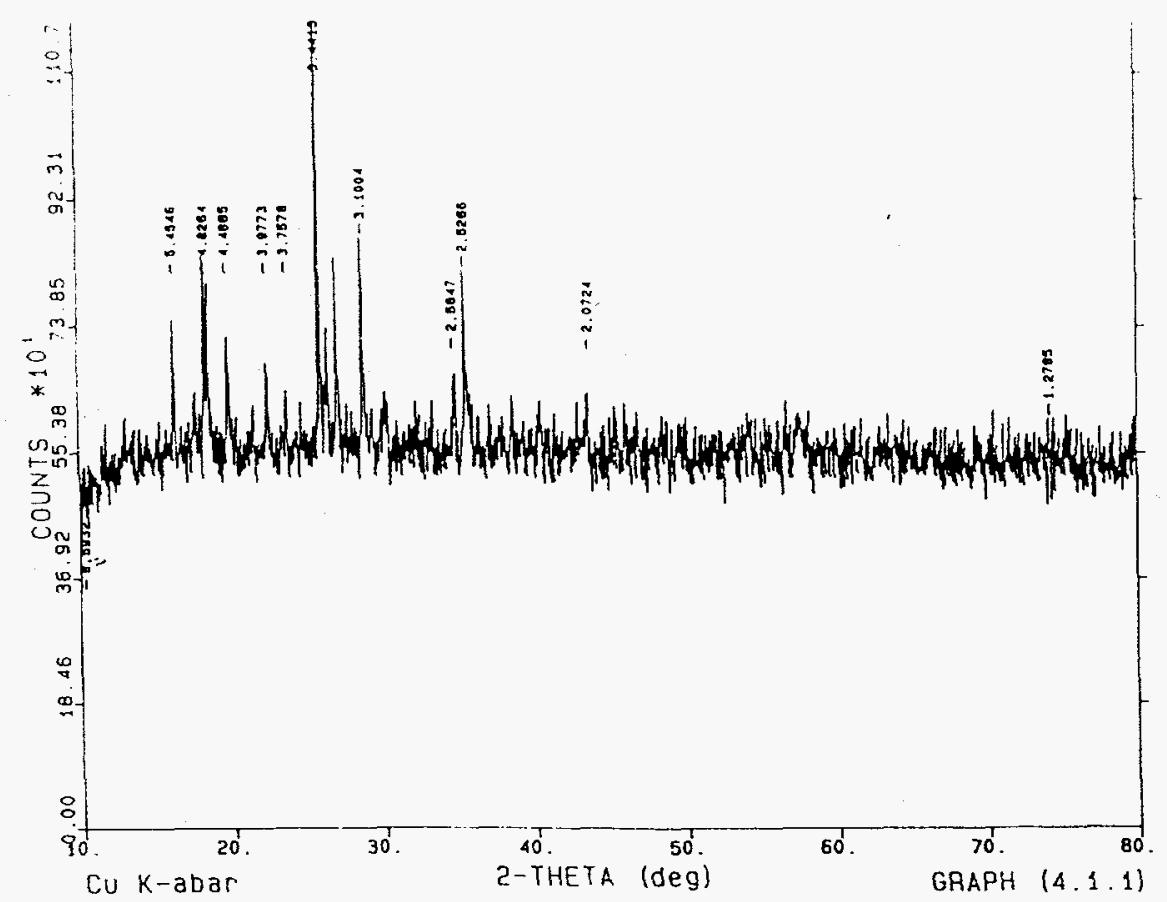

Figure 7:XRD spectrum of the deposition and reaction layer on the surface of the used ceramic filter.

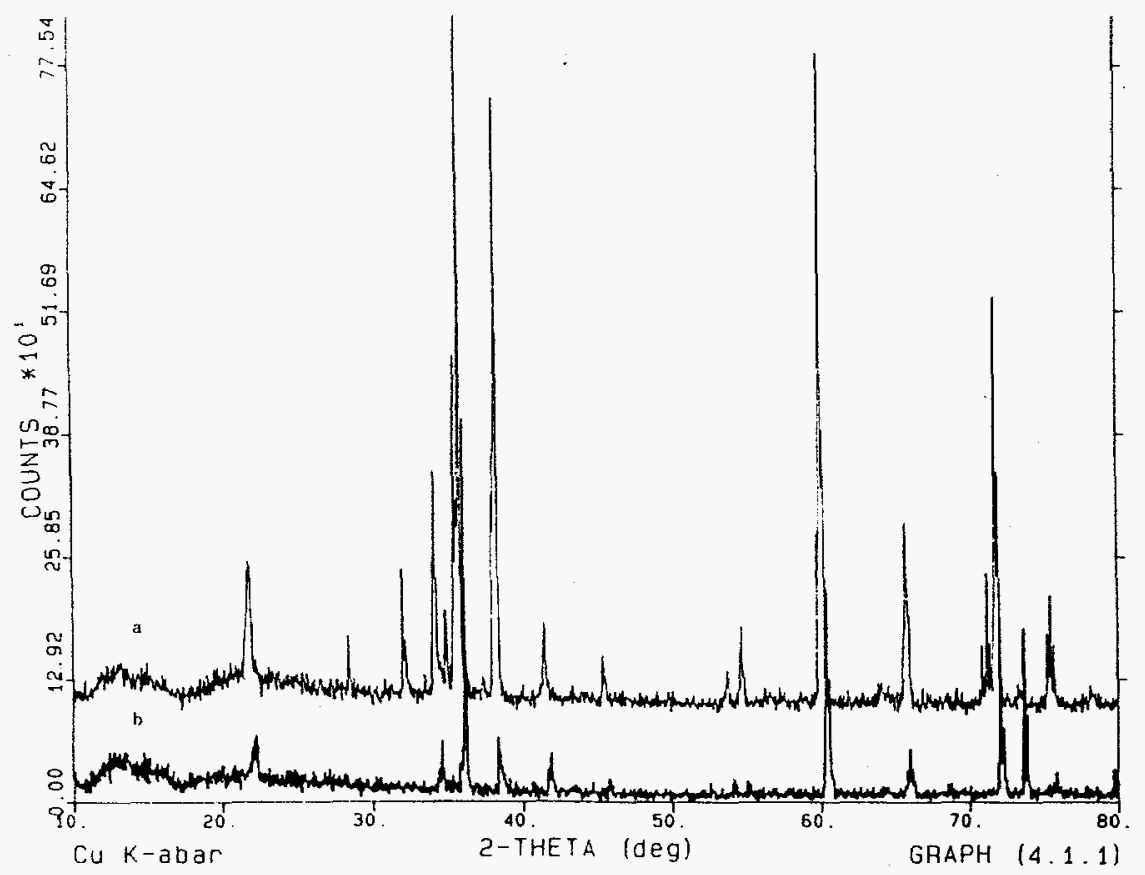

Figure 8 XRD spectra of the outer layers of (a) the used and (b) the unused ceramic filters, showing changes in crystal plane spaces after usage. 


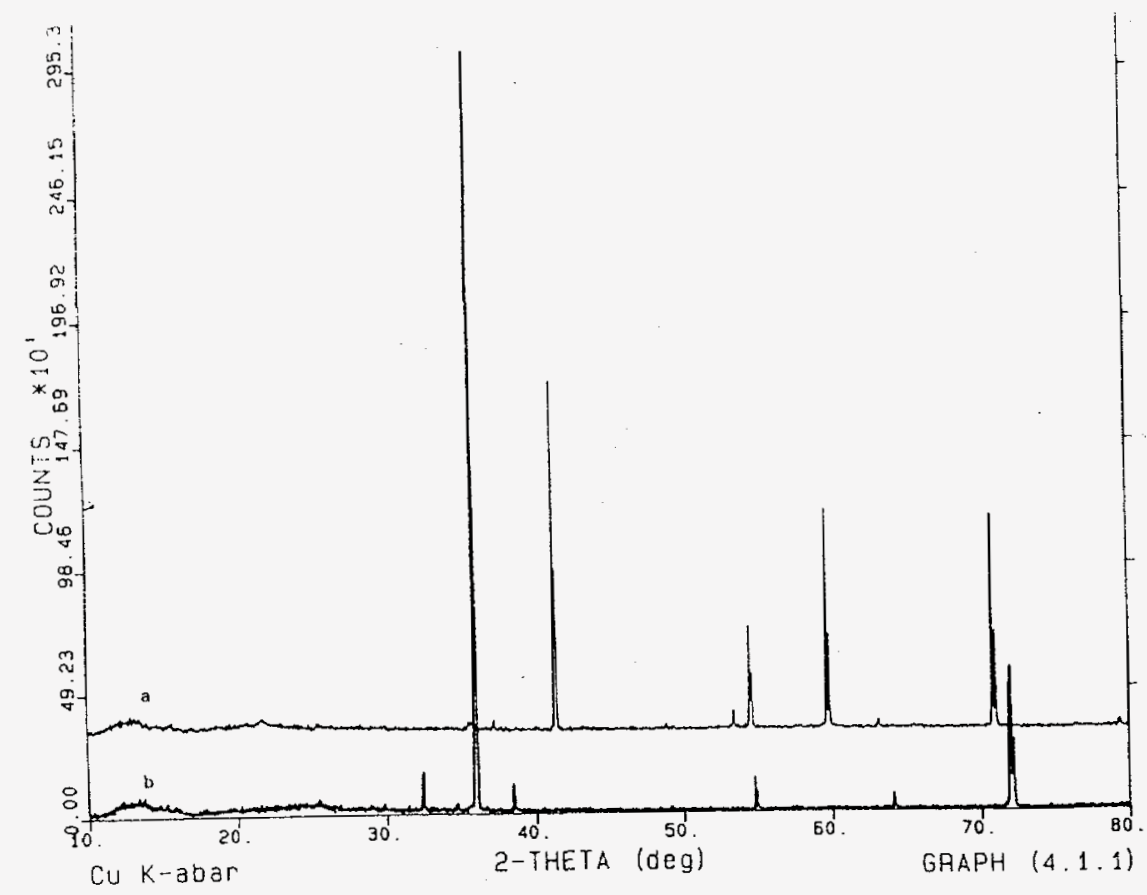

Figure 9 XRD spectra of the inner layers of (a) the used and (b) the unused ceramic filters, showing changes in crystal plane spaces and orientation after usage.

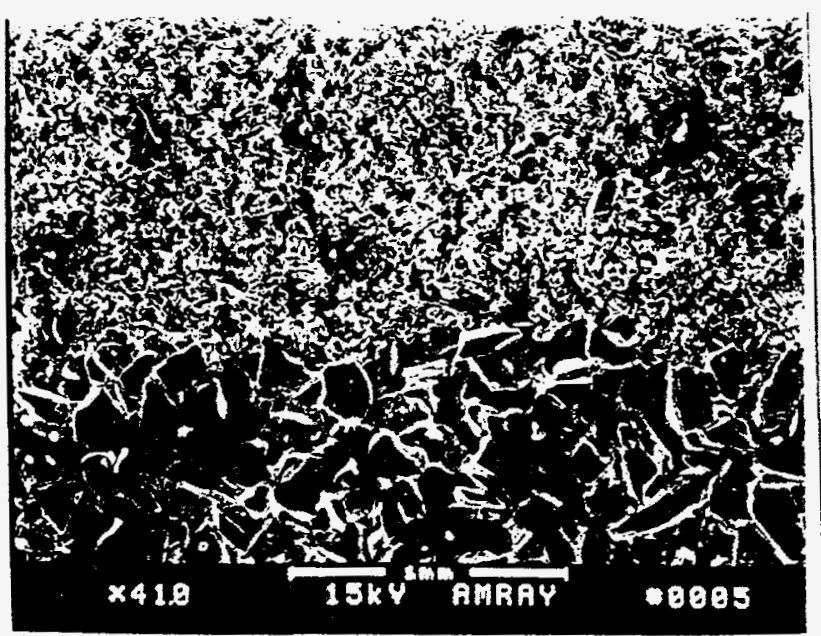

(a)

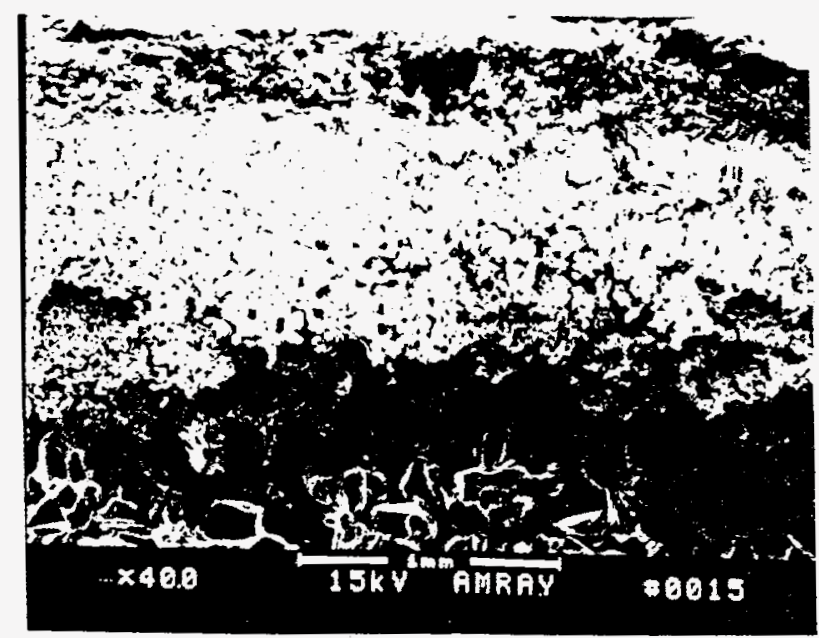

(b)

Figure 10 SEM micrographs of (a) the unused and (b) used ceramic filters showing the double layer structure. 


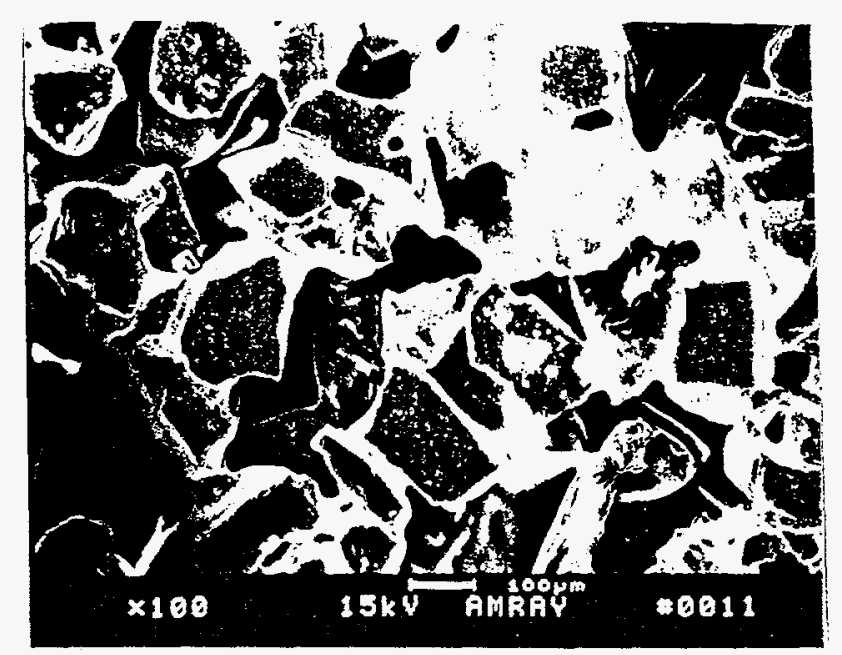

Figure $_{11}$ SEM micrographs of the unused ceramic filters showing the inclusion and defects.

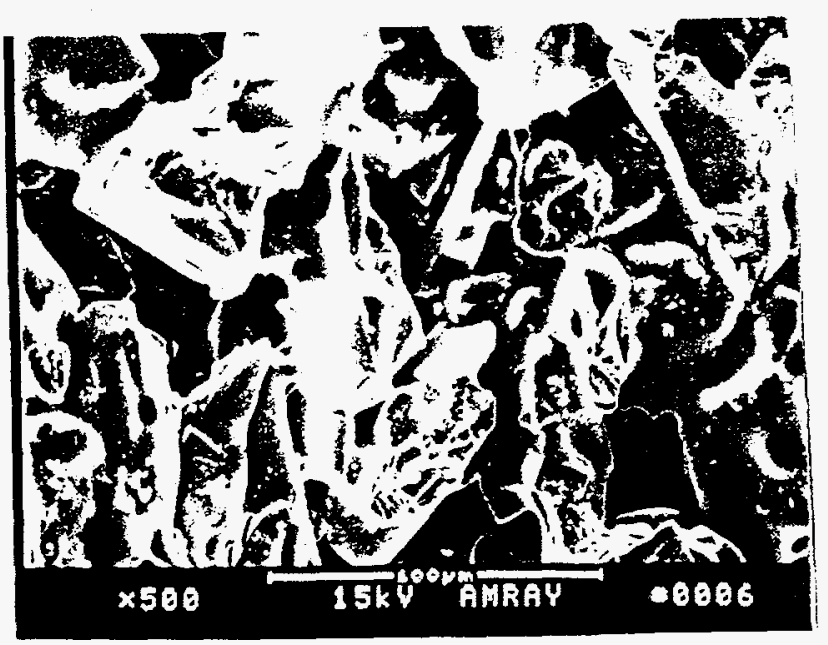

(a)

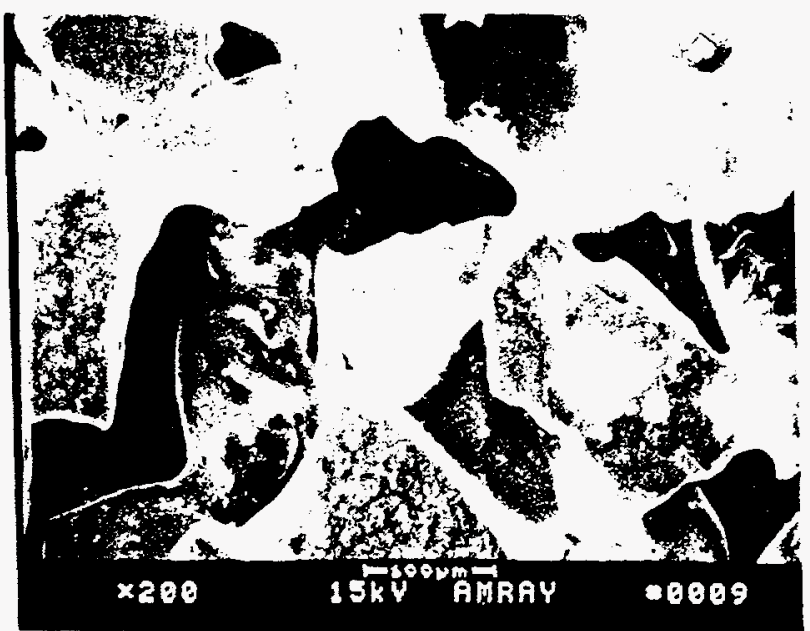

(b)

Figure12 SEM micrographs of (a) outer and (b) inner layers of the unused ceramic filters showing microstructural features: particle's and pore's shape and size. 


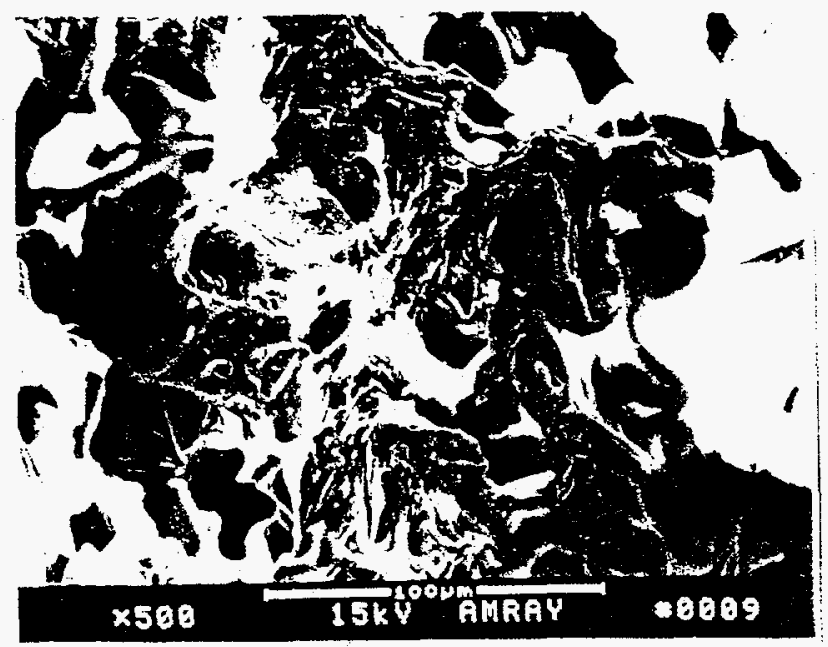

(a)

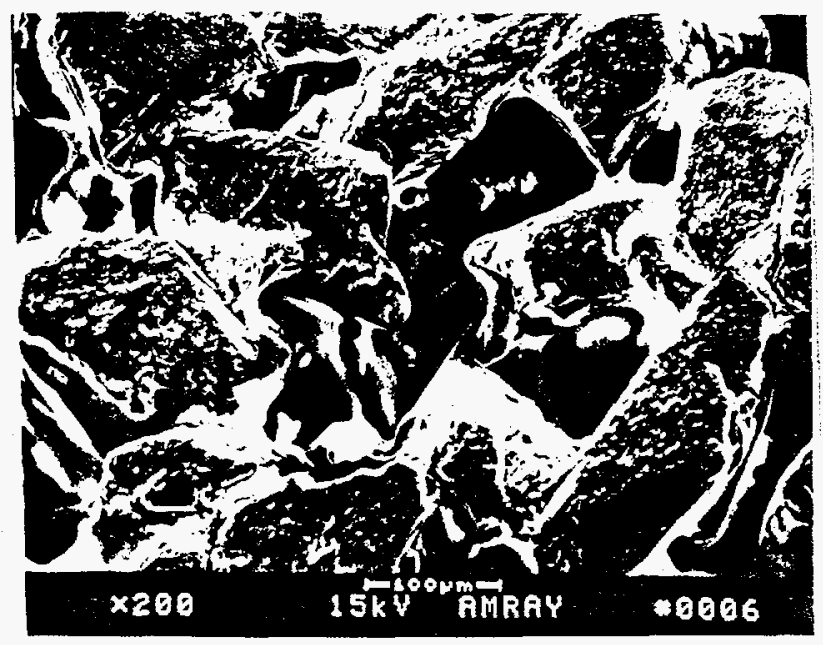

(b)

Figure 13SEM micrographs of (a) outer and (b) inner layers of the used ceramic filters showing microstructural features: particle's and pore's shape and size.

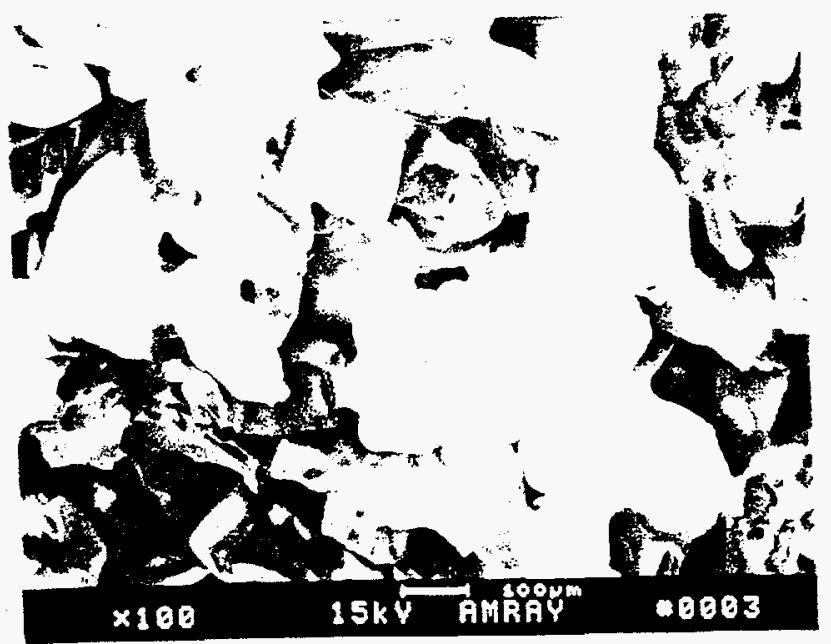

Figure 14 SEM micrographs of the failed ceramic filter showing morphological characteristics of the fractured surface. 